\title{
Síntese e caracterização de scaffolds de fibroína
}

\section{Synthesis and characterization of fibroin scaffolds}

\author{
Luísa Carvalho Pereira Araújo ${ }^{1}$, José Martins de Oliveira Júnior ${ }^{2}$, \\ Norberto Aranha ${ }^{2}$
}

\footnotetext{
${ }^{1}$ Graduada em Engenharia Química pela Universidade de Sorocaba - Uniso, Sorocaba, São Paulo, Brasil.

${ }^{2}$ Programa de Mestrado Profissional em Processos Tecnológicos e Ambientais - Uniso, Cidade Universitária Professor Aldo Vannucchi, 15-2101,7000, Sorocaba, São Paulo, Brasil.

e-mail: luisacarvalhoaraujo2@gmail.com, jose.oliveira@prof.uniso.br, norberto.aranha@prof.uniso.br
}

\section{RESUMO}

Este trabalho teve como objetivo diminuir o tempo de formação de hidrogéis de fibroína utilizados na produção de scaffolds para aplicações na área médica e odontológica. Para a extração da fibroína foram utilizados os solventes: brometo de lítio e uma solução ternária (cloreto de cálcio + álcool etílico + água). Realizaramse também modificações na membrana utilizada na diálise, de modo a diminuir o tempo para a formação de hidrogel e, consequentemente, obtenção dos scaffolds. A Tomografia por Transmissão de Raios-x confirmou a formação de scaffolds contendo $73,282 \%$ de porosidade total, sendo $73,272 \%$ de poros abertos interconectados, e densidade de conectividade entre os poros de 665,728 poros $/ \mathrm{mm}^{3}$. A microscopia óptica mostrou que a estrutura dos scaffolds é constituída por fios com diâmetro de $24 \mu \mathrm{m}$. Por meio da espectroscopia infravermelho (FTIR) foi possível confirmar a presença das bandas de Amida I, II e III, caraterísticas da fibroína, ao final do processo de extração. A análise de DSC apresentou dois picos endotérmicos em $60{ }^{\circ} \mathrm{C}$ e $297^{\circ} \mathrm{C}$ correspondentes à liberação de água e fusão da proteína, respectivamente. As modificações realizadas na membrana, proposta neste trabalho, diminuíram significativamente o tempo para a formação de hidrogel, precursor dos scaffolds, ocorrendo durante os três dias de diálise.

Palavras-chave: Biomateriais. Fibroína. Scaffolds. Hidrogéis.

\begin{abstract}
The aim of this work was to reduce the formation time of fibroin hydrogels used in the production of scaffolds for medical and dental applications. For the extraction of fibroin the solvents were used: lithium bromide and a ternary solution (calcium chloride + ethyl alcohol + water). Modifications were also made to the membrane used in the dialysis, in order to decrease the time for hydrogel formation and, consequently, obtaining the scaffolds. The Tomography by X-ray Transmission confirmed the scaffolds formation containing $73.282 \%$ total porosity, with $73.272 \%$ of open pores interconnected, and connectivity density between pores of 665,728 poros $/ \mathrm{mm}^{3}$. Optical microscopy showed the structure of the scaffolds is made up of wires with a diameter of $24 \mu \mathrm{m}$. Through infrared spectroscopy (FTIR) it was possible to confirm the presence of the Amida I, II and III bands, characteristics of fibroin, at the end of the extraction process. The DSC analysis showed two endothermic peaks at $60{ }^{\circ} \mathrm{C}$ and $297{ }^{\circ} \mathrm{C}$ corresponding to the water release and protein fusion, respectively. The membrane modifications proposed in this work significantly reduced the time for hydrogel formation, precursor of the scaffolds, occurring during the three days of dialysis.
\end{abstract}

Keywords: Biomaterials. Fibroin. Scaffolds. Hydrogels.

\section{INTRODUÇÃO}

Os biomateriais abrangem um grande número de diferentes tipos de materiais que têm sido estudados ao longo de décadas. Os avanços dos materiais sintéticos, técnicas cirúrgicas e métodos de esterilização têm permitido a utilização de biomateriais em muitos casos [1]. Tem-se, como exemplo, a aplicação de biomateriais sintéticos na regeneração do tecido ósseo, como uma alternativa aos enxertos ósseos, visto que estes não danificam tecidos saudáveis e não aumentam os riscos de contaminações virais e bacterianas [2]. 
Uma estrutura interessante para reconstituição óssea são os biomateriais na forma de scaffolds, que são estruturas porosas tridimensionais que servem de molde para o crescimento celular, ou seja, para a formação de um novo tecido ósseo [3]. Devem possuir um arranjo que mimetize os meios físicos e químicos do tecido saudável, para guiar a migração, diferenciação e proliferação tecidual [4]. Os scaffolds para regeneração óssea devem atender a certos critérios para desempenhar esta função, inclusive propriedades mecânicas semelhantes às do local da reparação óssea, a biocompatibilidade e biodegradabilidade, a uma taxa compatível com a remodelação [5].

Diversos estudos $[2,3,5,6]$ tem discutido o potencial de aplicações da fibroína de seda na reconstituição tecidual, sob a forma de scaffolds, o que torna a fibroína um biomaterial versátil para esse tipo de aplicação. Considerando a parte estrutural dessa proteína, a mesma se compõe por duas cadeias, uma de alto e outra de baixo peso molecular ( $325 \mathrm{kDa}$ e $25 \mathrm{kDa}$ respectivamente), e suas fibras possuem entre 10 e $25 \mu \mathrm{m}$ de diâmetro [6]. Além disso, a fibroína apresenta em seu arranjo molecular dois domínios: um amorfo, também chamado de seda I (silk I), e outro cristalino, ou seda II (silk II). Na seda I, o polipeptídio constituído por uma hélice- $\alpha$ é mantido por ligações de hidrogênio. Em contrapartida, a conformação em folha- $\beta$ é resultante da formação de pontes de hidrogênio entre dois ou mais polipeptídios adjacentes, resultando em uma estrutura termodinamicamente estável. Na seda II, têm-se uma série de repetições dos aminoácidos alanina e glicina, conectados por serina ou tirosina. A cadeia cristalina da fibroína contém uma estrutura secundária em folha- $\beta$, o que confere à proteína características como resistência à tração, por exemplo [7].

A extração da fibroína envolve basicamente três etapas: 1) separação da fibroína de outras proteínas, particularmente da sericina que envolve os fios de fibroína; 2) dissolução da fibroína; e 3) diálise. A solução obtida ao final deste processo é então gelificada formando, após sua liofilização, uma estrutura porosa e resistente mecanicamente $[8,9,10]$. Há na literatura diversos trabalhos que utilizam processos diferentes para separar a fibroína de outras proteínas existentes na formação do fio da seda. Para esta etapa alguns autores utilizam o aquecimento sob pressão a $120^{\circ} \mathrm{C}$ em autoclave [11,12], outros realizam uma lavagem em solução salina $[4,7]$. Assim, a etapa para a dissolução da fibroína, por sua vez, pode ser realizada por diferentes soluções como relatado por ROCKWOOD et al. (2011) [13].

Visto que a fibroína pode ser obtida por diferentes métodos, este trabalho tem como objetivo propor uma modificação na etapa de diálise, utilizando membranas com cut-off maior e submetendo-as a um tratamento prévio de lavagem, de modo a diminuir o tempo para a formação de scaffolds.

\section{MATERIAIS E MÉTODOS}

O método utilizado para extração da fibroína seguiu o protocolo descrito por ROCKWOOD et al. (2011) [13], o qual se divide em três etapas: diluição, diálise e centrifugação.

\subsection{Diluição}

Para a extração da fibroína foram cortados $5 \mathrm{~g}$ de casulos do bicho da seda Bombyx mori, e pesados $4,24 \mathrm{~g}$ de $\mathrm{Na}_{2} \mathrm{CO}_{3}$. Diluiu-se o carbonato em um béquer de $2 \mathrm{~L}$ contendo água ultrapura, sob agitação constante. Imergiram-se os casulos nesta solução, em aquecimento até a fervura, durante 35 min. Esta fase envolve a remoção de sericina e outras proteínas presentes em torno dos fios de fibroína, que são solúveis por meio de aquecimento em solução de carbonato de sódio $\left(\mathrm{Na}_{2} \mathrm{CO}_{3}\right)$ [14]. As fibras obtidas foram imersas em um béquer de 2L com água ultrapura, por $20 \mathrm{~min}$ (repetindo-se 3 vezes a lavagem), e colocadas em seguida em placa de Petri e levadas à estufa por $24 \mathrm{~h}$, com temperatura de $50^{\circ} \mathrm{C}$.

\subsubsection{Solvente ternário}

As fibras foram lavadas em solução aquosa de $\mathrm{Na}_{2} \mathrm{CO}_{3} 0,5 \%(\mathrm{~m} / \mathrm{v})$. Preparou-se a solução ternária salina para diluição, em um béquer de $1 \mathrm{~L}$ sob agitação constante, onde $60 \mathrm{~g}$ de cloreto de cálcio dihidratado foram dissolvidos em 44,14ml de água ultrapura e depois adicionados 47,60ml de álcool etílico. Aguardou-se até que o sal se dissolvesse totalmente na solução. Num béquer de $1 \mathrm{~L}$ foram adicionados $50 \mathrm{ml}$ da solução ternária $\mathrm{CaCl}_{2} \cdot 2 \mathrm{H}_{2} \mathrm{O}-\mathrm{CH}_{3} \mathrm{CH}_{2} \mathrm{OH}-\mathrm{H}_{2} \mathrm{O}$ (proporção 1:2:6 molar) [15] para cada $5 \mathrm{~g}$ de fibras de seda obtidas na etapa anterior. $\mathrm{O}$ béquer contendo a mistura foi imerso em equipamento para banho-maria QUIMIS®, numa temperatura de $85^{\circ} \mathrm{C}$ durante aproximadamente $20 \mathrm{~min}$. A solução resultante tornou-se inteiramente líquida, um pouco viscosa e de aspecto amarelado. 


\subsubsection{Solvente 9,3 M Brometo de Lítio ( $\mathrm{LiBr}$ )}

De acordo com a molaridade referida $(9,3 \mathrm{M})$, foram adicionados 40,38g de $\mathrm{LiBr}$ em $50 \mathrm{ml}$ de água ultrapura, para preparo da solução. A quantidade de $\mathrm{LiBr}$ e água variam com a quantidade experimental necessária. A proporção segundo a literatura é de $1 \mathrm{~g}$ de fibra de fibroína seca para $4 \mathrm{ml}$ de $9,3 \mathrm{M} \mathrm{LiBr}$ [16], então, para $5 \mathrm{~g}$ de fibras iniciais adicionam-se $20 \mathrm{ml}$ de solvente. Como a solução de brometo de lítio tem um maior poder de dissolução da fibroína, logo imergidas nesta solução, a fibras se decompõe rapidamente. A mistura já totalmente líquida é deixada em agitação constante à $60^{\circ} \mathrm{C}$, por $4 \mathrm{~h}$. Ao final se obtém uma solução pouco viscosa e levemente amarelada.

\subsection{Diálise}

A diálise é uma etapa importante do processo e para este trabalho utilizou-se uma membrana de celulose MWCO 12.000 Da, da marca Sigma.

$\mathrm{O}$ processo de diálise, é fundamental para a remoção do sal $\left(\mathrm{CaCl}_{2} \cdot 2 \mathrm{H}_{2} \mathrm{O}\right.$ ou $\left.\mathrm{LiBr}\right)$ e outras impurezas contidas na solução de fibroína. Também considerada a etapa crítica, já que pode ocasionar a passagem do sal como também da fibroína para fora da membrana, por isso essa fase merece atenção. No caso do solvente ternário, o álcool se evapora no processo de diluição.

\subsubsection{Membrana sem tratamento}

No primeiro teste a membrana foi utilizada sem tratamento prévio, ou seja, a membrana foi apenas lavada em água destilada e em seguida preenchida com a solução de fibroína. Para cada $15 \mathrm{~cm}$ de membrana, aproximadamente, inseriu-se $12 \mathrm{ml}$ de solução de fibroína. Imergiu-se, cada tubo de diálise, em béqueres com 1L de água ultrapura, sob agitação magnética constante. A água do béquer foi trocada após $1 \mathrm{~h}$. Trocou-se novamente após 8 horas, totalizando 6 trocas de água durante as $48 \mathrm{~h}$ seguintes. Ao final do processo obtém-se uma solução de fibroína pouco viscosa.

\subsubsection{Membrana com tratamento}

Em um segundo teste, a membrana foi tratada previamente, sendo inicialmente lavada em água corrente durante 3 a 4 horas. Logo, esta foi transferida para uma solução de $0,3 \%(\mathrm{~m} / \mathrm{v})$ de sulfeto de sódio a $80^{\circ} \mathrm{C}$ por 1 minuto e lavada em água corrente a $60^{\circ} \mathrm{C}$ durante 2 minutos. Na etapa seguinte a membrana foi acidificada com uma solução de ácido sulfúrico a $0,2 \%$ (v/v) e enxaguada com água quente para remoção do ácido. Por fim, foi armazenada em recipiente com água ultrapura a temperatura ambiente.

A diálise seguiu o mesmo procedimento descrito no item 2.2.1 acima sendo que, neste caso, no segundo dia de diálise é possível observar a formação de um corpo sólido denominado hidrogel [17, 18]. Durante esta diálise a solução restante tornou-se mais viscosa, formando um gel.

\subsection{Centrifugação}

A solução de fibroína obtida na etapa 2.2 .1 foi colocada em tubos falcon de $60 \mathrm{ml}$, os quais foram transferidos para uma centrífuga Thermo SCIENTIFIC®, modelo Sorvale ST 16R Centrifuge, sob rotação de 11.000 RPM durante 30 minutos. Após esse tempo formou-se um precipitado que é removido dos tubos. A solução é novamente centrifugada nas mesmas condições, resultando num total de $1 \mathrm{~h}$ de centrifugação. Nesta segunda etapa praticamente não foi observada a formação de precipitado no fundo dos frascos. Caso haja a formação de precipitado uma nova centrifugação é realizada para garantir a pureza final da solução de fibroína. Se não for utilizada logo em seguida, a solução é armazenada em geladeira a temperatura na faixa de 5 a $10^{\circ} \mathrm{C}$.

No caso de diálise com membrana tratada (item 2.2.2), forma-se ao final do processo um hidrogel imerso em um gel no interior da membrana. $\mathrm{O}$ hidrogel é retirado, lavado rapidamente com água destilada para retirar o excesso de gel na sua superfície, e transferido para geladeira para posterior congelamento e liofilização. O gel restante é submetido ao mesmo processo de centrifugação e armazenagem descrito acima.

\subsection{Concentração de fibroína na solução}

Mediu-se o valor das massas em todas as etapas do procedimento, aplicou-se a fórmula do "Título", também conhecida como "Porcentagem em massa de uma solução", à qual se refere à relação entre a massa do soluto $\left(m_{1}\right)$ e a massa da solução $(m)$, segundo a equação: 


$$
\tau=\frac{m_{1}}{m} \cdot 100 \%
$$

\subsection{Obtenção de scaffolds}

As amostras foram armazenadas na forma de gel e hidrogel em moldes, no congelador a $-4^{\circ} \mathrm{C}$ por $48 \mathrm{~h}$. Em seguida os moldes foram transferidos para o biofreezer à $-80^{\circ} \mathrm{C}$ durante 4 dias. Após esse período as amostras congeladas foram liofilizadas, permanecendo por $48 \mathrm{~h}$ a uma temperatura de $-50^{\circ} \mathrm{C}$. Em seguida as amostras foram retiradas do liofilizador, analisadas visualmente e com o auxílio de microscópio óptico.

\subsection{Caracterização}

As amostras foram caracterizadas em um Tomógrafo por Transmissão de Raios-X com resolução de 19,5 $\mu$ m, num equipamento da Bruker microCT, modelo SkyScan 1174, utilizando tensão de $29 \mathrm{KV}$, corrente de 661 $\mu \mathrm{A}$ e filtro de Alumínio com 0,25 mm de espessura; espectroscopia na região do infravermelho - FTIR, utilizando um espectrofotômetro de transformada de Fourier da Perkin Elmer, modelo Spectrum 65; e calorimetria diferencial de varredura utilizando um DSC-60, marca Shimadzu.

\section{RESULTADOS E DISCUSSÃO}

Em função das variações no processo de síntese, obtiveram-se resultados diferenciados quanto a formação de solução, hidrogel e gel de fibroína.

A utilização de membrana de diálise sem tratamento prévio (apenas com lavagem em água destilada) resultou numa solução de fibroína ao final da diálise. A obtenção de hidrogel a partir dessa solução requer um tempo de diálise maior (5 a 10 dias), de modo a elevar a viscosidade da solução e provocar a cristalização das cadeias de fibroína. Este acaba sendo um processo mais demorado e de custo um pouco mais elevado.

A formação de hidrogel ocorre, com maior facilidade e rapidez (três dias), quando se utiliza a membrana tratada segundo as etapas descritas no item 2.2.2 acima. Este resultado se deve ao aumento no tamanho dos poros da membrana devido ao tratamento recebido. Isto acelera a retirada do sal presente na solução aumentando a quantidade de água em contato com as cadeias da fibroína no interior da membrana. A água, segundo a literatura, favorece a cristalização das cadeias de fibroína com a formação de folhas $\beta$ [19].

O tamanho dos poros da membrana é um ponto importante na formação do hidrogel. Geralmente, o que se reporta na literatura é a utilização de membranas de $3.500 \mathrm{Da}$, que é suficientemente permeável para permitir que os sais e a água permeiem livremente pela sua parede, mantendo no interior da membrana as cadeias curtas e longas de fibroína [10].

Neste trabalho foram utilizadas membranas com cu-off de 12.000 Da que, juntamente com seu tratamento químico prévio, acelera o processo de diálise fazendo com que as cadeias mais curtas de fibroína sejam retiradas com maior rapidez. Isto resulta em uma maior concentração de cadeias longas de fibroína no interior da membrana reduzindo, deste modo, o tempo para a formação dos scaffolds.

A síntese com brometo de lítio formou apenas solução de fibroína ao final de três dias de diálise. Nesta extração com o brometo de lítio $(9,3 \mathrm{M})$, o processo foi o mesmo que o realizado com o solvente ternário $\left(\mathrm{CaCl}_{2} \cdot 2 \mathrm{H}_{2} \mathrm{O}-\mathrm{CH}_{3} \mathrm{CH}_{2} \mathrm{OH}-\mathrm{H}_{2} \mathrm{O} ; 1: 2: 6\right.$ molar) [20]. Este resultado se deve ao maior poder de dissolução do brometo de lítio. Segundo a literatura [10] a dissolução da fibroína em soluções salinas depende da concentração de sal e aumenta na seguinte ordem: a) para ânions: sulfato < citrato < tartarato < acetato < cloreto < nitrito < brometo < iodeto < tiocianato < dicloroacetato; b) para cátions: $\mathrm{Ca}^{2+}<\mathrm{Sr}^{2+}<\mathrm{Ba}^{2+}<\mathrm{Li}^{+}<\mathrm{Zn}^{2+}$.

A solução de LiBr utilizada nas mesmas condições de processo (temperatura e tempo) que a solução ternária, faz com que ocorra uma maior quebra das cadeias da proteína. Isto resulta, ao final do processo de dissolução, em um maior número de cadeias mais curtas de fibroína. Esta solução, dialisada agora com membranas de 12.000 Da e previamente tratadas quimicamente contém, provavelmente, uma menor concentração de cadeias da proteína com tamanho suficiente para formação do hidrogel, o que justificaria o resultado obtido.

\subsection{Concentração de fibroína na solução}

A determinação da concentração de fibroína foi realizada apenas para a massa da solução liofilizada, onde se obteve o soluto puro, no caso a fibroína pura, que representou $m_{l}=4,40605 \mathrm{~g}$, e a massa da solução final de fibroína, que indica a massa da solução $(m=48,1887 \mathrm{~g})$. Sendo assim, a concentração de fibroína na solução equivale a $9,1433 \%$. O resultado apresenta-se próximo ao relatado na literatura, que é de 10\% [18]. Porém, o 
resultado não obteria $10 \%$ devido à perda de massa, que envolve a remoção de outra proteína, sericina, contida nos casulos.

\subsection{Microscopia óptica}

As amostras de géis e hidrogéis foram coletadas e transferidas para moldes. Após liofilização, avaliou-se a conformação estrutural dos scaffolds. Notou-se que estes obtidos a partir dos géis ao serem visualizados em microscópio óptico, apresentavam uma estrutura pouco porosa e com fibras desconexas e quebradiças, como mostra a Figura 1. Os scaffolds dos hidrogéis formaram matrizes porosas que analisados no microscópio óptico (Fig. 2-c) apresentam-se como um emaranhado de fios de fibroína, com cadeias extensas. Os fios possuem diâmetro médio de $24 \mu \mathrm{m}$, correspondendo a faixa relatada na literatura [18] que varia de 10 a $25 \mu \mathrm{m}$.

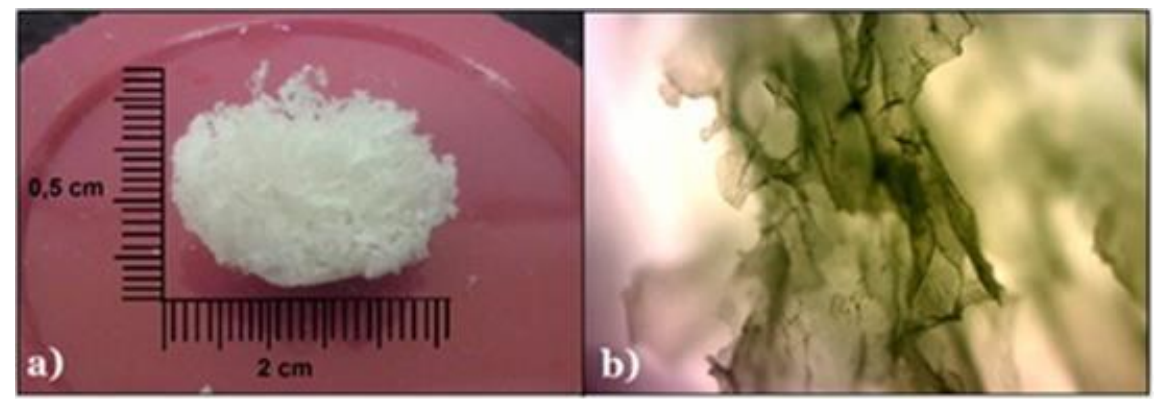

Figura 1: a) Scaffold a partir de gel de fibroína e b) Visualização microscópica do scaffold, aumento 100x.

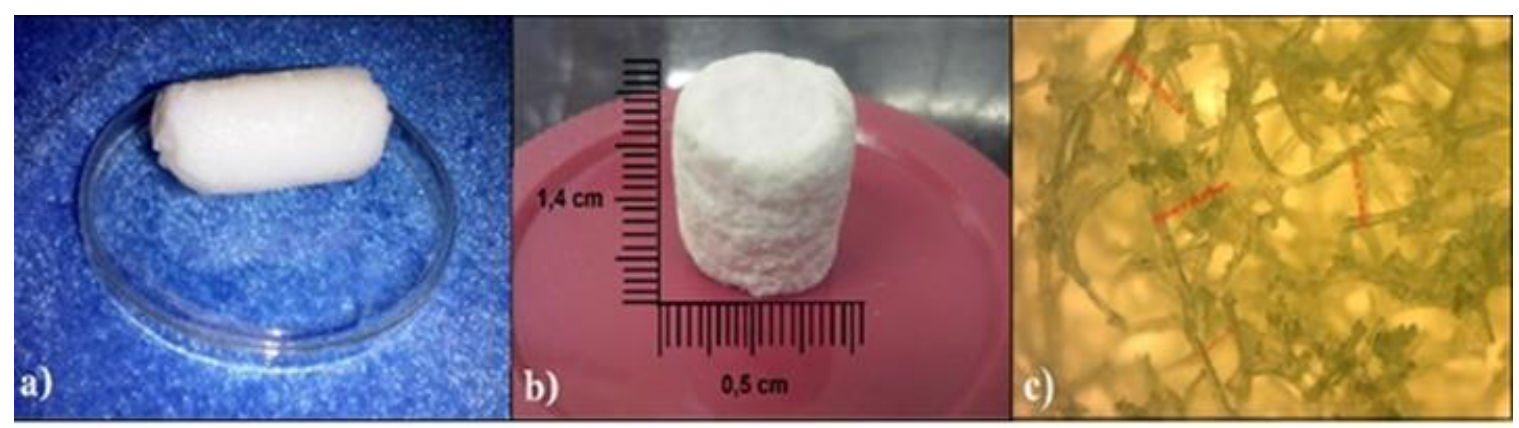

Figura 2: a) Hidrogel; b) Scaffold a partir de hidrogel liofilizado e c) fios de fibroína contidos no scaffold, aumento 100x.

\subsection{Tomografia de Raios-X}

Além da técnica da microscopia óptica utilizou-se também a Tomografia por Transmissão de Raios-X para analisar os scaffolds de hidrogel, com a qual se pôde analisar a estrutura da amostra representada pela Figura 3. Nesta figura é possível observar claramente a obtenção de um material poroso, bem como a interconectividade entre seus poros.

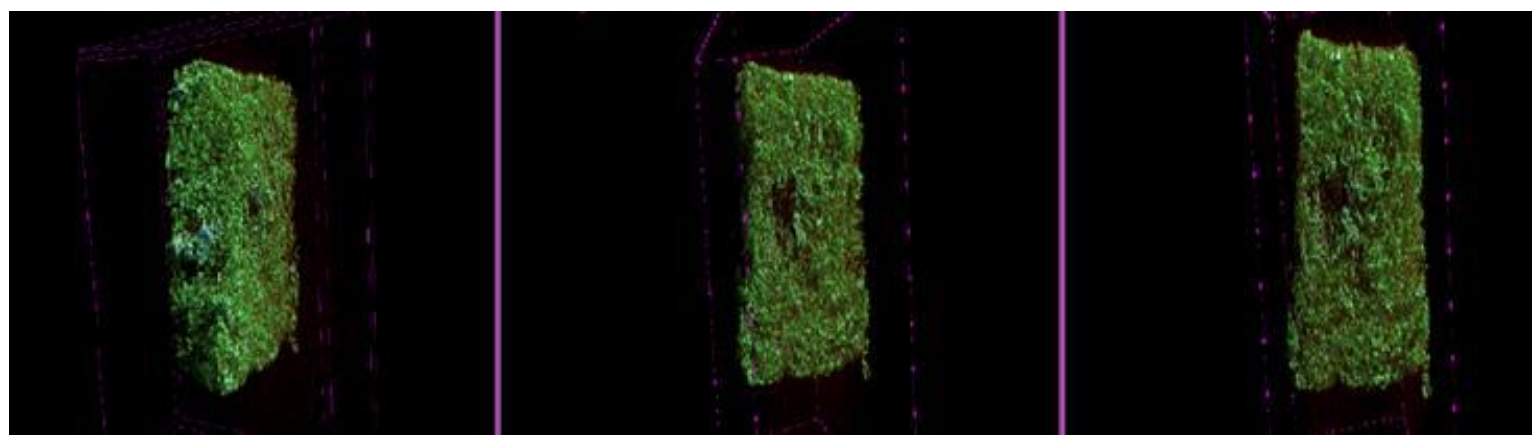

Figura 3: Tomografia de raios-X em três ângulos diferentes do scaffold obtido a partir do hidrogel.

Esta amostra com $10,034 \mathrm{~mm}^{3}$ e área superficial de $30,534 \mathrm{~mm}^{2}$, apresentou $73,282 \%$ de porosidade total, sendo $73,272 \%$ de poros abertos interconectados. A densidade de conectividade entre os poros foi de 
665,728 poros $/ \mathrm{mm}^{3}$. A quantidade de poros fechados (não conectados) correspondeu a 0,037\% do volume total da amostra, valor este que pode ser desprezado comparando-se com a porcentagem de poros abertos. Na superfície da amostra, com uma área de $32,727 \mathrm{~mm}^{2}$, foi observada a presença de poros fechados correspondendo a um total de $0,297 \mathrm{~mm}^{2}$.

Estes valores são importantes, pois a proliferação celular no interior do scaffold para a formação de novo tecido ósseo só ocorrerá se os poros, desde a superfície da amostra até seu interior, forem abertos e interconectados. Portanto, os resultados obtidos para o scaffold de hidrogel produzido neste trabalho indicam que este material apresenta condições, do ponto de vista estrutural, para ser utilizado em restaurações ósseas.

\subsection{Espectroscopia na região do infravermelho}

A espectroscopia na região do infravermelho é uma ferramenta muito versátil e útil para informar sobre as estruturas de proteínas, obtida da análise da banda de amida I que ocorre na região de $1.700-1.600 \mathrm{~cm}^{-1}$. Esta banda é bastante complexa, pois envolve estruturas secundárias ( $\alpha$-hélice, folhas $\beta$, voltas $\beta$ e irregulares), e está relacionada principalmente com o estiramento $\mathrm{C}=\mathrm{O}$. A amida II corresponde a deformação angular no plano do grupo $\mathrm{N}-\mathrm{H}(60 \%)$ e pelo estiramento $\mathrm{C}-\mathrm{N}(40 \%)$. A banda referente a esta amida aparece em torno de $1.550 \mathrm{~cm}^{-1}$. A amida III, cuja banda pode ser observada na região de $1.230-1.300 \mathrm{~cm}^{-1}$, resulta da combinação das vibrações de estiramento do $\mathrm{N}-\mathrm{C}$ e de flexão do grupo $\mathrm{C}=\mathrm{O}$, e está relacionada à conformação de folha- $\beta$ [19].

A Figura 4 mostra o espectro infravermelho da fibroína que foi liofilizada. Neste, pode-se observar a presença das bandas características desta proteína. Têm-se claramente as três bandas referentes aos grupos amida, correspondentes à amida I em $1.643 \mathrm{~cm}^{-1}$, amida II em $1.518 \mathrm{~cm}^{-1}$ e amida III em $1.234 \mathrm{~cm}^{-1}$.

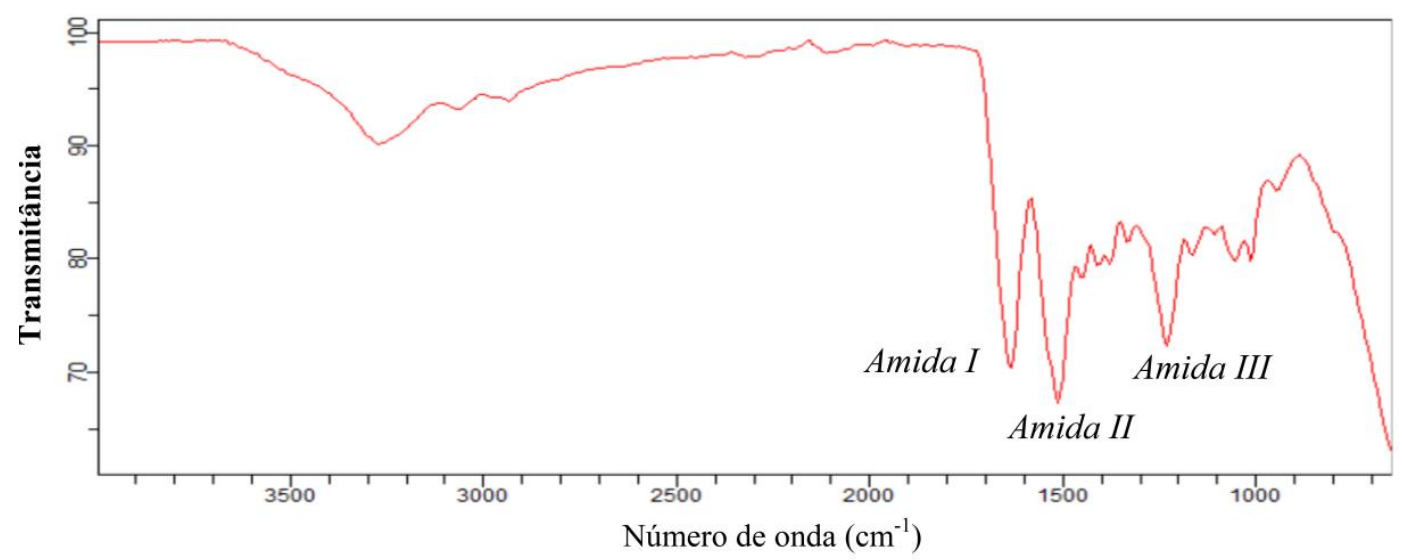

Figura 4: Espectro infravermelho da fibroína liofilizada, com a presença das bandas características referentes aos grupos amida I, II e III. [2, 7]

Os espectros das amostras obtidas com a solução de 9,3 M LiBr e com o solvente ternário são apresentados na Figura 5. O espectro referente ao scaffold obtido via solução ternária (Figura 5B) apresentou-se semelhante ao da Figura 4, onde se observa claramente a presença das três bandas referentes às amidas I, II e III, respectivamente em $1.683 \mathrm{~cm}^{-1}, 1.558 \mathrm{~cm}^{-1} \mathrm{e} 1.249 \mathrm{~cm}^{-1}$.

A amostra de fibroína obtida via solução de brometo de lítio (Figura 5A), apresentou a banda referente à amida I um pouco deslocada, em $1.708 \mathrm{~cm}^{-1}$. A banda da amida III, um pouco mais intensa, está presente em $1.249 \mathrm{~cm}^{-1}$. No espectro a banda da amida II está presente em $1560 \mathrm{~cm}^{-1}$, porém, não se observa claramente esta banda como nos demais espectros. Esta diferença deve-se provavelmente ao fato do LiBr ser um solvente mais agressivo do que a mistura ternária, o que provocaria maior alteração na estrutura da cadeia da proteína.

\subsection{Calorimetria exploratória diferencial - DSC}

A análise DSC foi realizada em amostras com $2 \mathrm{mg}$, de gel e hidrogel de fibroína, cujas curvas são apresentadas nas Figuras 6 e 7. As duas amostras exibem curvas semelhantes, sendo que o primeiro pico endotérmico observado para as duas amostras, acorre em $60^{\circ} \mathrm{C}$ e correspondente ao início da evaporação da água. Fora este pico devido à água, as amostras não apresentaram qualquer outra transição térmica até a temperatura de $280^{\circ} \mathrm{C}$, resultado considerado importante para um biomaterial, pois demonstra que até essa faixa de tempera- 
tura não ocorre decomposição do material. Estes corroboram com os estudos relatados na literatura que mostram a decomposição de biopolímeros entre $280^{\circ} \mathrm{C}$ e $300^{\circ} \mathrm{C}$, aproximadamente $[9,21]$.

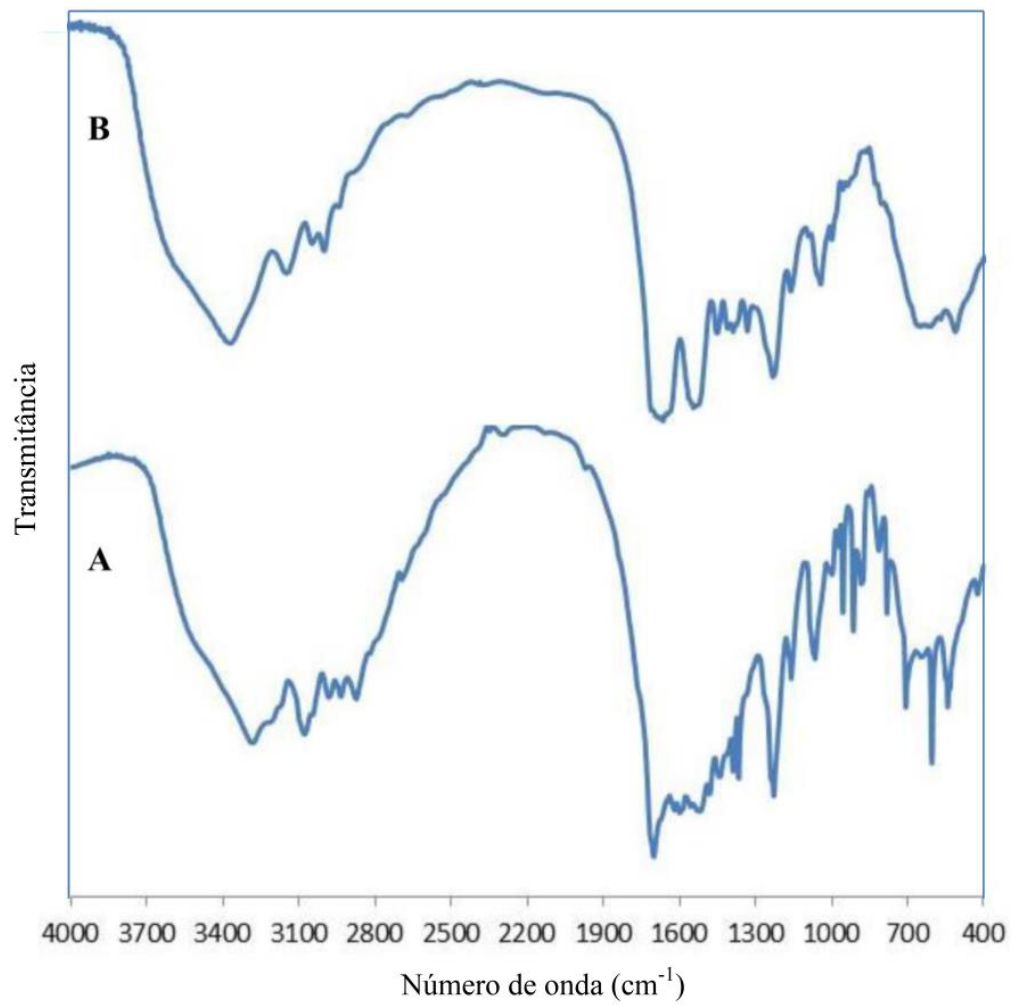

Figura 5: Espectro de Infravermelho para amostras de scaffolds utilizando-se A) solvente 9,3 M BrLi e B) solvente ternário. (n ${ }^{\circ}$ de scans: 64 , resolução: 4 ).

Um segundo pico endotérmico é observado em $297^{\circ} \mathrm{C}$, que corresponde ao ponto de fusão da fibroína [19]. Este sinal aparece mais intenso no DSC do scaffold obtido a partir do hidrogel, provavelmente devido a maior concentração de fibroína presente nesta estrutura. O comportamento de decomposição ocorrido nessas amostras são semelhantes aos observados em materiais de seda não orientados com estrutura de folha $\beta$ [21, 22]. A formação dessas estruturas de folha $\beta$ são importantes pois servem como ligações cruzadas, estabilizando as moléculas de fibroína [9].

Os resultados de DSC, assim como os espectros infravermelho, são importantes, pois confirmam a presença da fibroína ao final do processo de extração e nos scaffolds.

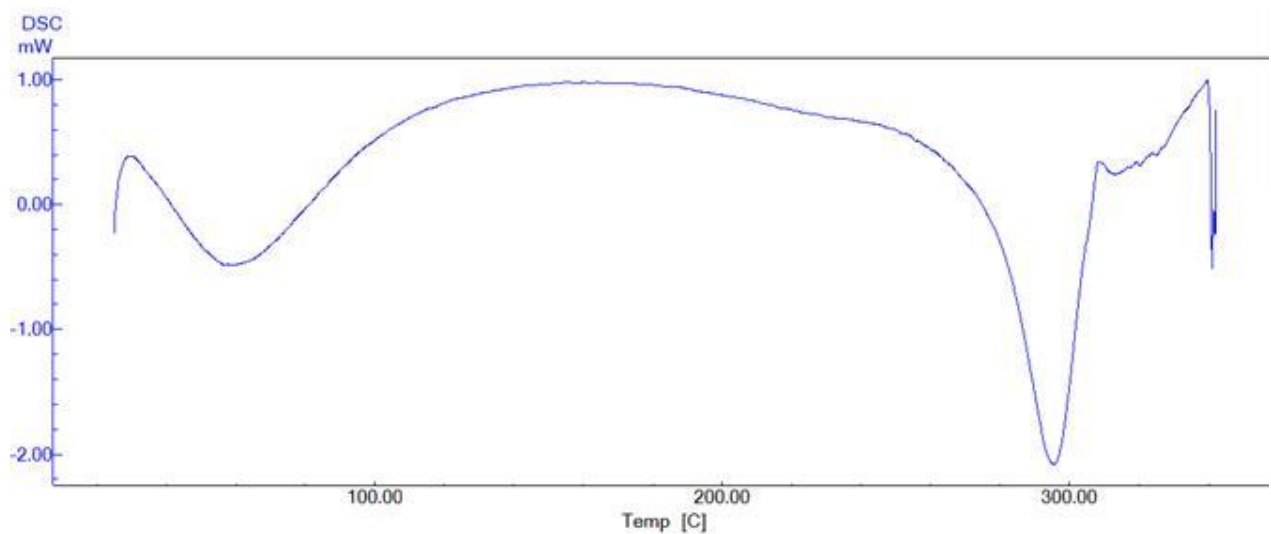

Figura 6: Curva DSC obtida para a amostra de hidrogel de fibroína (taxa de aquecimento de $10^{\circ} \mathrm{C} / \mathrm{min}$, nitrogênio atm). 


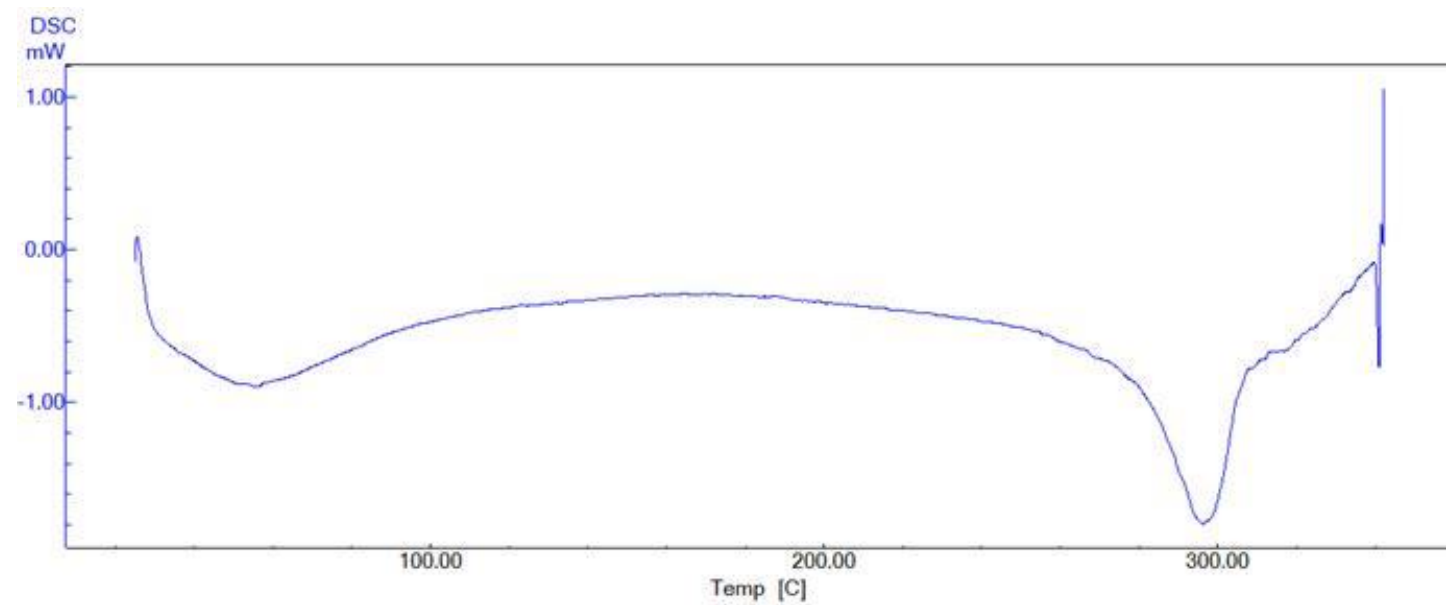

Figura 7: Curva DSC obtida para a amostra de gel de fibroína (taxa de aquecimento de $10^{\circ} \mathrm{C} / \mathrm{min}$, nitrogênio atm).

\section{CONCLUSÕES}

A proposta do trabalho em produzir scaffolds em um menor tempo foi atingida, onde se conseguiu um produto final com alto grau de porosidade e reprodutibilidade do processo. Os resultados mostraram a viabilidade em utilizar membranas, com poros maiores e submetidas a um tratamento químico prévio, na formação de scaffolds de fibroína. O emprego dessas membranas permitiu a formação de gel e de hidrogel durante a diálise em apenas três dias, tempo este bem menor do que o relatado na literatura. $\mathrm{O}$ mesmo resultado, porém, não se repetiu quando a solução ternária é substituída pelo brometo de lítio, o qual inviabiliza a gelificação da solução de fibroína durante sua diálise. Este resultado se deve ao fato deste reagente apresentar maior poder de dissolução das fibras, em comparação com o solvente ternário utilizado no trabalho.

As técnicas de FTIR e DSC confirmaram a presença de fibroína ao final da extração, com as variações de processo utilizadas. O scaffold do hidrogel liofilizado apresentou-se totalmente poroso, com poros interconectados desde a sua superfície, que pôde ser visualizado pela Tomografia por Transmissão de Raios-X. A análise por microscopia óptica mostrou que esta estrutura é composta por fios com diâmetro médio de $24 \mu \mathrm{m}$. Os scaffolds obtidos a partir do gel liofilizado aparentaram-se menos porosos, com fibras desconectadas, e mecanicamente mais frágeis devido a presença de cadeias mais curtas de fibroína.

\section{AGRADECIMENTOS}

Ao CNPq pela bolsa PIBIC. À Fapesp pelo apoio financeiro. À Uniso pela disponibilidade dos laboratórios para a síntese e caraterização das amostras.

\section{BIBLIOGRAFIA}

[1] KIM U.J., PARK J., KIM H.J., et al., "Three-dimensional aqueous-derived biomaterial scaffolds from silk fibroin", Biomaterials, v. 26, pp 2775-2785, 2005.

[2] OLADEJI O., IGE, LASISI E. U., SUNDAY A., Review Article Natural Products: A Minefield of Biomaterials, ISRN Materials Science, Article ID 983062, p. 20, 2012.

[3] LIU, X., MA, P.X., "Polymeric Scaffolds for Bone Tissue Engineering", Ann. Biomed. Eng., v.32, n.3, pp.477-486, 2004.

[4] RINA N., HYOUNG-JOON J., DAVID L. K., "Porous 3-D Scaffolds from Regenerated Silk Fibroin", Biomacromolecules, v.5, pp 718-726, 2004.

[5] HUTMACHER D.W., SCHANTZ J.T., LAM C.X.F., et al.,"State of the art and future directions of scaffold-based bone engineering from a biomaterials perspective", J. Tissue Eng. Regen. M., v.1, n.4, pp 245-260, 2007.

[6] ALTMAN, G. H., HORAN, R. L., BRAMONO, D. S., et al., "Biological and biomechanical assessment of a long-term bioresorbable silk-derived surgical mesh in an abdominal body wall defect model", Journal of the American College of Surgeons, v.205, pp S53-S54, 2007.

[7] KIM U.J., PARK J., KIM H.J., et al., "Three-dimensional aqueous-derived biomaterial scaffolds from silk fibroin”, Biomaterials, v.26, pp 2775-2785, 2005. 
[8] YU Q., HUI W., KAI W., et al., “A Review of Structure Construction of Silk Fibroin Biomaterials from Single Structures to Multi-Level Structures”, International Journal of Molecular Sciences, v.18, pp 2-21, 2017.

[9] KIM M. H., PARK W. H., "Chemically cross-linked silk fibroin hydrogel with enhanced elastic properties, biodegradability, and biocompatibility”, International Journal of Nanomedicine, v.11, pp. 2967-2978, 2016.

[10] SASHINA,E. S., BOCHEK,A. M., NOVOSELOV, N. P., et al., "Structure and Solubility of Natural Silk Fibroin”, Russian Journal of Applied Chemistry, v. 79, n. 6, pp 869-876, 2006.

[11] NAMRATHA S., ROOPINI K. D., NANDAN M., et al., "Extraction \& characterization of sericin and its immobilization on hydroxylapatite nanoparticles for tissue engineering applications", International Journal of ChemTech Research, v.7, n. 5, pp 2117-2124, 2015.

[12] PORNANONG, A., SORADA, K., TITPAWAN, N., et al., "The Effect of Sericin from Various Extraction Methods on Cell Viability and Collagen Production”, International Journal of Molecular Sciences, v.11, pp 2200-221, 2010.

[13] ROCKWOOD N. D., PREDA R. C., YÜCEL T., et al., "Materials fabrication from Bombyx mori silk fibroin”, Nature Protocols, v.6, n.10, pp 1612, 2011.

[14] VASCONCELOS, A. J. C., Protein matrices for wound dressings, Tese de D.Sc., Uminho, Minho, Portugal, 2010.

[15] KAVICZ, M. H., Preparação e caracterização de membranas obtidas a partir de fibroína de seda e poli (álcool vinílico), Tese de M.Sc., USP, São Carlos, Brasil, 2013.

[16] TRAIAN, V. C., ZEKE, Z., DAMIEN G. H., et al., "Bombyx mori Silk Fibroin Membranes as Potential Substrata for Epithelial Constructs Used in the Management of Ocular Surface Disorders", Tissue Engineering, part A, v.14, n.7, 2008.

[17] FERREIRA, A. V. F., Incorporation of Elastase Inhibitor in Silk Fibroin Nanoparticles for Transdermal Delivery, Tese de D.Sc., Uminho, Minho, Portugal, 2013.

[18] BEXIGA, N. M., Preparo e avaliação comparativa das propriedades físico-químicas de hidrogéis de fibroína de seda com conteúdo variado de sericina obtidos a partir dos cloreto de cálcio e lítio em sistemas distintos de solventes, Tese de M.Sc., USP, São Paulo, Brasil, 2014.

[19] MORAES, M. A., NOGUEIRA, G. M., WESKA, R. F., BEPPU, M. M., “Obtenção e caracterização de blendas de fibroína de seda e quitosana", In: Anais do $10^{\circ}$ Congresso Brasileiro de Polímeros, Foz do Iguaçu, PR, Outubro, 2009.

[20] BEPPU, M. M., SILVA, F. M., "Síntese e caracterização de hidrogéis de fibroína da seda com aditivos", http://www.bv.fapesp.br/pt/bolsas/53252/sintese-e-caracterizacao-de-hidrogeis-de-fibroina-da-seda-comaditivos/. Acessado em julho de 2017.

[21] FREDDI, G., PESINA, G., TSUKADA, M., "Swelling and dissolution of silk fibroin. (Bombyx mori) in N-methyl morpholine N-oxide”, Int J Biol Macromol, v. 24, n.2-3, pp 251, 1999.

[22] UM, I. C., KWEON, J. Y., PARK, Y. H., et al., "Structural characteristics and properties of the regenerated silk fibroin prepared from formic acid”, Int J Biol Macromol, v.29, n.2, pp 91-97, 2001. 